\title{
The genetic architecture of phosphorus efficiency in sorghum involves pleiotropic QTL for root morphology and grain yield under low phosphorus availability in the soil
}

Karine C. Bernardino ${ }^{1,2}$, Maria Marta Pastina' ${ }^{2}$ Cícero B. Menezes' ${ }^{1}$ Sylvia M. de Sousa', Laiane S. Maciel ${ }^{1,3}$, Geraldo Carvalho Jr ${ }^{1,5}$, Claudia T. Guimarães ${ }^{1}$, Beatriz A. Barros ${ }^{1}$, Luciano da Costa e Silva', Pedro C. S. Carneiro², Robert E. Schaffert', Leon V. Kochian ${ }^{4}$ and Jurandir V. Magalhaes ${ }^{1,3^{*}}$ (D)

\begin{abstract}
Background: Phosphorus (P) fixation on aluminum (Al) and iron (Fe) oxides in soil clays restricts $\mathrm{P}$ availability for crops cultivated on highly weathered tropical soils, which are common in developing countries. Hence, P deficiency becomes a major obstacle for global food security. We used multi-trait quantitative trait loci (QTL) mapping to study the genetic architecture of $\mathrm{P}$ efficiency and to explore the importance of root traits on sorghum grain yield on a tropical low-P soil.
\end{abstract}

Results: $\mathrm{P}$ acquisition efficiency was the most important component of P efficiency, and both traits were highly correlated with grain yield under low $\mathrm{P}$ availability. Root surface area was positively associated with grain yield. The guinea parent, SC283, contributed 58\% of all favorable alleles detected by single-trait mapping. Multi-trait mapping detected 14 grain yield and/or root morphology QTLs. Tightly linked or pleiotropic QTL underlying the surface area of fine roots (1-2 $\mathrm{mm}$ in diameter) and grain yield were detected at positions 1-7 megabase pairs $(\mathrm{Mb})$ and $71 \mathrm{Mb}$ on chromosome 3, respectively, and a root diameter/grain yield QTL was detected at $7 \mathrm{Mb}$ on chromosome 7. All these QTLs were near sorghum homologs of the rice serine/threonine kinase, OsPSTOL1. The SbPSTOL 1 genes on chromosome 3, Sb03g006765 at $7 \mathrm{Mb}$ and S603g031690 at $60 \mathrm{Mb}$ were more highly expressed in SC283, which donated the favorable alleles at all QTLS found nearby S6PSTOL1 genes. The Al tolerance gene, SbMATE, may also influence a grain yield QTL on chromosome 3. Another PSTOL1-like gene, S607g02840, appears to enhance grain yield via small increases in root diameter. Co-localization analyses suggested a role for other genes, such as a sorghum homolog of the Arabidopsis ubiquitin-conjugating E2 enzyme, phosphate 2 (PHO2), on grain yield advantage conferred by the elite parent, BRO07 allele.

(Continued on next page)

\footnotetext{
* Correspondence: jurandir.magalhaes@embrapa.br

'Embrapa Milho e Sorgo, Rodovia MG 424, km 65, Caixa Postal 151, Sete Lagoas, MG 35701-970, Brazil

${ }^{3}$ Departamento de Biologia Geral, Universidade Federal de Minas Gerais, Avenida Presidente Antônio Carlos, 6627, Belo Horizonte, MG 31270-901, Brazil

Full list of author information is available at the end of the article
}

(C) The Author(s). 2019 Open Access This article is distributed under the terms of the Creative Commons Attribution 4.0 International License (http://creativecommons.org/licenses/by/4.0/), which permits unrestricted use, distribution, and reproduction in any medium, provided you give appropriate credit to the original author(s) and the source, provide a link to the Creative Commons license, and indicate if changes were made. The Creative Commons Public Domain Dedication waiver (http://creativecommons.org/publicdomain/zero/1.0/) applies to the data made available in this article, unless otherwise stated. 
(Continued from previous page)

Conclusions: Genetic determinants conferring higher root surface area and slight increases in fine root diameter may favor P uptake, thereby enhancing grain yield under low-P availability in the soil. Molecular markers for SbPSTOL 1 genes and for QTL increasing grain yield by non-root morphology-based mechanisms hold promise in breeding strategies aimed at developing sorghum cultivars adapted to low-P soils.

Keywords: Phosphorus deficiency, Phosphorus stress, Acid soils, Root system architecture

\section{Background}

Sorghum is a versatile crop that was domesticated in the tropics, in the northeastern quadrant of the African continent, possibly at least 5000 years ago [1]. Along with pearl millet, sorghum is the main staple food crop of the West African Savannah zones and in that region, guinea sorghums are broadly adapted to different stresses, including those caused by poor soil fertility [2]. In sub-Saharan Africa, two of the most important abiotic stresses that limit sorghum production are $\mathrm{Al}$ toxicity and low-P availability in the soil [3-5].

Both types of abiotic stresses share a common chemical basis centered on the prevalence of $\mathrm{Al}$ and Fe oxides in the clay fraction of highly weathered tropical soils [6]. Under low $\mathrm{pH}, \mathrm{Al}$ is hydrolyzed into the ionic form, $\mathrm{Al}^{3+}$, which damages plant roots, reducing crop yields [7]. Low-P availability, in turn, results from $\mathrm{P}$ fixation with $\mathrm{Al}$ and Fe oxides [8]. Plant roots absorb $\mathrm{P}$ from the soil solution in the orthophosphate forms, $\mathrm{H}_{2} \mathrm{PO}_{4}{ }^{-}$and $\mathrm{HPO}_{4}{ }^{2-}$ [9]. However, P fixation into soil clays impairs P diffusion from the soil solution towards the root surface, restricting uptake. Approximately half of the world agricultural lands have low-P availability [10]. Even in high input production systems, the non-renewable nature of phosphatic rock fertilizer [11] raises questions regarding the sustainability of continuously increasing rates of P fertilizer applications, which are needed to sustain crop yields. Therefore, in view of the prevalence of low-P soils in agricultural frontiers in which food production needs continuous improvement, such as in Africa, the identification of genetic factors that can be used to facilitate breeding for sorghum adaptation to low-P conditions become of utmost importance for global food security.

Aluminum tolerance in sorghum is due to the action of the Al-induced and Al-activated root citrate transporter, SbMATE, which underlies the aluminum tolerance locus, $A l t_{S B}$, at the terminal region of sorghum chromosome 3 [12]. Recently, the SbMATE allele donated by the guinea sorghum, SC283, has been shown to enhance sorghum grain yield by over 1.0 ton ha ${ }^{-1}$ on an acid, Al toxic soil, with no detectable yield penalty in the absence of Al toxicity [13]. Leiser et al. [5], using $A l t_{S B}$-specific markers, also found strong associations of SbMATE with grain yield production, particularly in
low-P conditions in many environments in West-Africa. This suggests that SbMATE confers $\mathrm{P}$ use efficiency (PUE) in addition to Al tolerance, possibly via a joint effect of citrate mobilizing $\mathrm{P}$ that is fixed on the soil clays [14], and by enhancing root development in $\mathrm{Al}$ tolerant genotypes, increasing $\mathrm{P}$ uptake [15].

The ability of a plant to grow and to produce reasonable levels of grain and biomass under low-P availability, which we designate here as $\mathrm{P}$ use efficiency (PUE, or simply $P$ efficiency), can be achieved via different mechanisms acting to optimize utilization of internal $\mathrm{P}$ or to enhance $\mathrm{P}$ acquisition [16]. From the crop physiology standpoint, these mechanisms may result from the modulation of $\mathrm{P}$ transporters, organic acid exudation, phosphatase secretion, mycorrhizae associations and alterations in root system architecture in response to low-P conditions, among other mechanisms (reviewed by López-Arredondo et al. [17]). For maize cultivated on a tropical low-P soil, $\mathrm{P}$ acquisition has been reported to be more important than $\mathrm{P}$ internal utilization to explain differences in $\mathrm{P}$ use efficiency [16], which was also confirmed by QTL mapping results [18]. These studies emphasize the importance of changes in root system architecture and morphology as a mechanism favoring $\mathrm{P}$ acquisition (reviewed by Magalhaes et al. [19]). These modifications may involve changes in lateral root growth and angle, presence of shallow roots, in addition to enhanced proliferation of root hairs $[10,17,20]$.

There is a recent body of evidence suggesting that genes modulating root morphology may result in increased $\mathrm{P}$ efficiency. Overexpression of the rice serine/threonine receptor-like kinase, phosphorus starvation tolerance1 (OsPSTOL1, [21]) has been shown to increase grain yield in rice cultivated on a low-P soil via OsPSTOL1-elicited enhancement of early root growth, which favors $\mathrm{P}$ uptake in the developing rice plant. Subsequently, association mapping established that allelic variation at homologs of OSPSTOL1 in sorghum, designated as SbPSTOL1 genes, was associated with enhanced grain yield production on a low-P soil, likely via changes in root morphology, particularly root diameter and root surface area [22]. In addition, recent studies in Arabidopsis suggested a role in P efficiency for genes involved with Al tolerance, such as the 
malate transporter, ALMT1 [23] and its regulatory factor, the $\mathrm{C}_{2} \mathrm{H}_{2}$-type zinc finger, sensitive to proton rhizotoxicity 1 (AtSTOP1 [24]), in addition to the ABC-like transporter, aluminum sensitive 3 (ALS3 [25, 26]). These genes appear to mediate an iron-dependent mechanism leading to enhancement of lateral root growth [27-31], which can possibly increase P uptake on acidic soils [15].

Using a genetic approach based on multi-trait QTL mapping, the present study aimed at unravelling the genetic architecture of $\mathrm{P}$ efficiency in a large sorghum recombinant inbred line population, and to establish links between the genetics and physiology of P efficiency, such as associations between root morphology, $\mathrm{P}$ content and sorghum grain yield on soils with low-P availability.

\section{Results}

Phenotypic analyses in the parents and RIL population

The most important trait for P efficiency within a breeding context, grain yield in the field, was assessed under low-P availability in the soil. We also estimated the relative contributions of the efficiency at which a plant acquires $P$ from the soil ( $\mathrm{P}$ acquisition efficiency, $\mathrm{PAE}$ ) and also internal utilization efficiency (PUTIL), on overall $\mathrm{P}$ use efficiency (PUE or simply P efficiency, that encompasses both PAE and PUTIL) [16, 32]. Table 1 shows that PAE was the most important component influencing PUE for sorghum cultivated under low-P availability in the soil. Acquisition efficiency accounted for $82 \%$ of the variability in PUE, whereas the contribution of the PUTIL component was comparatively much smaller (18\%). Therefore, we also assessed root morphology in hydroponics as changes in root morphology including increased root length can lead to enhanced P uptake and grain yield in soils with low-P availability. To gain insights into sorghum performance in hydroponics, we also assessed dry matter accumulation (DM) and shoot and root $\mathrm{P}$ content.

We observed substantial genetic variance for all traits assessed in the present study, with heritability estimates ranging from 0.3 (root diameter - RD) to 0.8 (plant height - PH, Additional file 1). Traits reflecting sorghum

Table 1 Relative importance of PAE and PUTIL over PUE assessed in low-P conditions field

\begin{tabular}{lclcc}
\hline Trait & $\begin{array}{l}\text { Correlation } \\
\left(r_{x i y}\right)^{a}\end{array}$ & $\begin{array}{l}\text { Standard Deviation } \\
(S)\end{array}$ & $S x_{i} / S_{y}$ & $\begin{array}{l}\text { Relative } \\
\text { importance }\end{array}$ \\
\hline PAE (x1) & 0.9216 & 0.2285 & 0.8868 & 0.82 \\
PUTIL (x2) & 0.4763 & 0.0999 & 0.3878 & 0.18 \\
PUE (y) & & 0.255 & &
\end{tabular}

arxiy: Phenotypic correlation among Phosphorus acquisition efficiency (PAE) and Phosphorus internal utilization efficiency (PUTIL) and Phosphorus use efficiency (PUE) performance grown on low-P growth media measured in nutrient solution (DM and P content) and in the field (grain yield - Gy) showed intermediate to high heritability estimates of between 0.4 and $\sim 0.8$, indicating reasonable experimental precision to detect regions of the sorghum genome associated with P efficiency. Marked transgressive segregation for grain yield in the recombinant inbreed line (RIL) population, where a maximum of 4.5 ton $\mathrm{ha}^{-1}$ exceeded by more than two-fold the grain yield for either parent (Additional file 1), emphasizes the rather complex, polygenic nature of $\mathrm{P}$ efficiency measured in sorghum cultivated under low-P availability in the soil.

We measured total root surface area (SA) of the sorghum root system and also the root surface area of roots within the diameter classes of $0-1,1-2$ and $2-4.5 \mathrm{~mm}$, which are designated hereafter as very fine, fine and thicker roots, respectively. BR007 tended to exhibit greater total root surface area and had thinner roots compared to SC283 (Fig. 1a-d), which is due to the prevalence in BR007 of roots in the $0-1 \mathrm{~mm}$ diameter class (Fig. 1e - labeled SA1). These very fine roots comprise most of the root system in both parents but are more prevalent in BR007 (80\%) compared to SC283 (73\%) (Fig. 1e). However, when measured in the different root diameter classes, root surface area turned out to be heterogeneous between the parents, with SC283 showing higher surface area of both fine (SA2) and thicker (SA3) roots (Fig. 1f-g) compared to BR007. However, fine roots are still far more prevalent $(\sim 17 \%)$ than thicker roots $(\sim 1 \%)$ in the SC283 root system. Finally, the most important trait to reflect $\mathrm{P}$ efficiency, grain yield under low-P availability in the soil, was approximately $12 \%$ higher for the guinea race parent, SC283, compared to BR007 (Additional file 1 and Fig. 1h).

\section{Trait associations}

PAE and PUE were both highly correlated with grain yield $(r=0.85$ and 0.97 , respectively; Additional file 2), which is consistent with the importance of $\mathrm{P}$ acquisition on P use efficiency (Table 1). PUTIL, which we found to be a minor component of PUE compared to acquisition efficiency (Table 1), was less correlated with grain yield $(r=0.4)$.

Next, we studied the association between root morphology traits and grain yield under low-P availability in the soil via a genetic correlation analysis (Fig. 2). Total root surface area was highly correlated with total root length (correlation coefficient, $r=0.98$ ) and surface area of very fine roots (SA1) $(r=0.99)$. In addition, surface area of fine roots (SA2) was highly correlated with root volume $2(r=1.0)$. Therefore, among those traits, root surface area was used to gain insights into the role of root morphology on grain yield under low-P availability in the soil. A reduction in root diameter was in general 


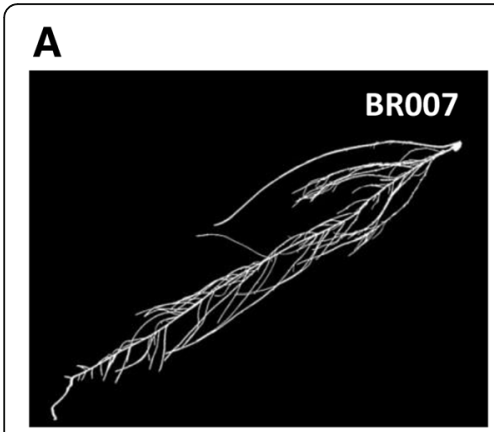

B

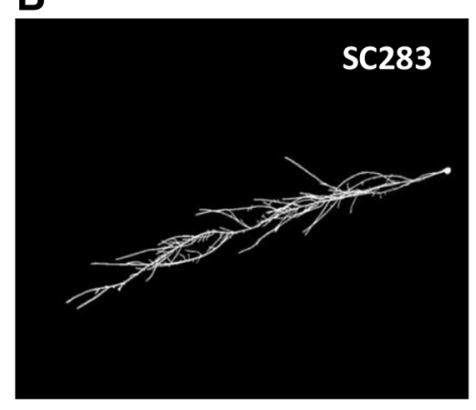

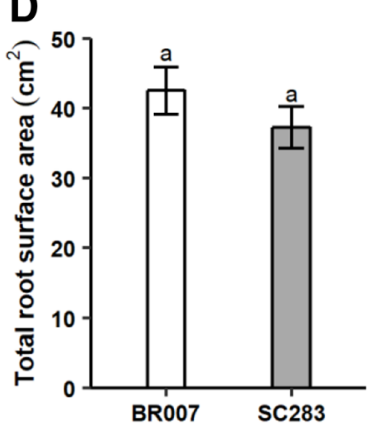

E
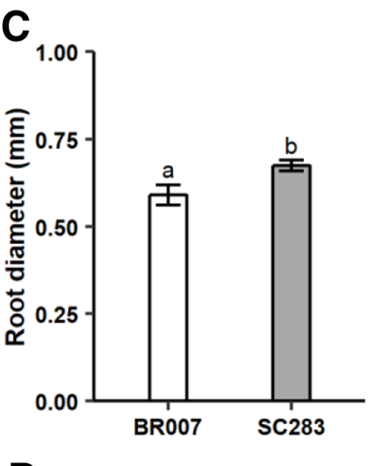

D

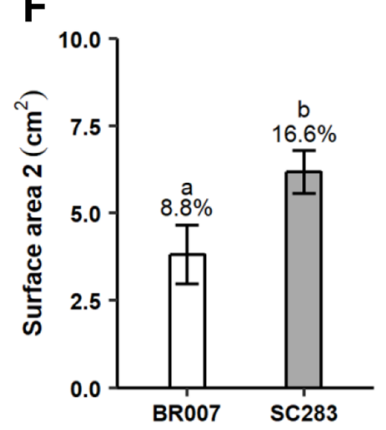

G
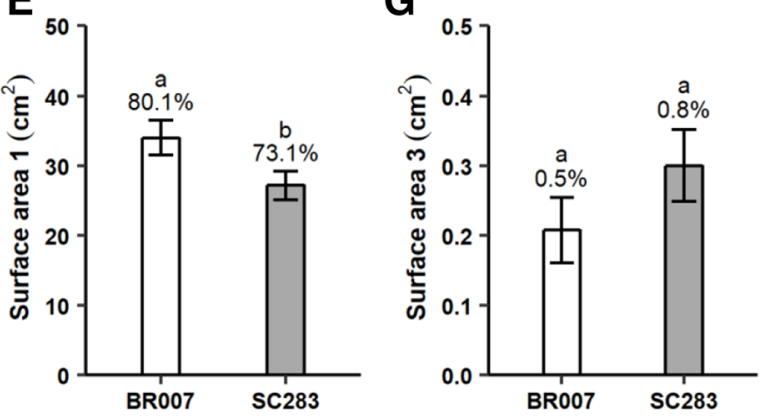

H

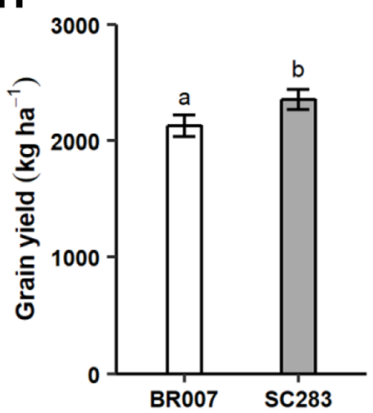

Fig. 1 Phenotypic characterization of the RIL parents. Images of the (a) BR007 and (b) SC283 root systems. Phenotypic means for (c) root diameter (RD), $\mathbf{d}$ total root surface area (SA), surface area of roots in the diameter classes of (e) 0-1 mm, (SA1, designated as very fine roots), $\mathbf{f}$ 1-2 mm (SA2, fine roots) and (g) 2-4.5 mm (SA3, thicker roots). All surface area measures are in $\mathrm{cm}^{2}$. Root images and root morphology traits were assessed after 13 days in nutrient solution with low-P. $\mathbf{h}$ Grain yield (Gy) was assessed in a low-P soil with one hundred twenty reps. The proportion of roots within each diameter class relative to total surface area of the root systems are shown as percentages in $\mathbf{e}, \mathbf{f}$ and $\mathbf{g}$. Error bars are shown. Different letters indicated statistical differences by the t-test ( $p$-values $\leq 0.10$ )

associated with increased total root surface area $(r=-0.46)$, which was driven primarily by very fine roots (RD vs. SA1, $r=-0.53$ ) and, to a lesser extent, by thicker roots (RD vs. SA3, $r=-0.23)$. This suggests the existence of some genetic determinants that act to increase root surface area via enhanced development of finer roots. However, the magnitude of the correlation coefficients also indicates that root surface area and root diameter are controlled to some extent independently. Surface area of fine roots was positively but weakly correlated with root diameter (RD vs. SA2, $r=0.1$ ), suggesting that slight increases in root diameter between 1 and $2 \mathrm{~mm}$ may result in enhanced surface area. Grain yield under low-P availability in the soil was significantly correlated with the different traits reflecting surface area of fine roots $(r \cong 0.1$, $p$-value $<0.05)$, although this association tended to dissipate with thicker roots between 2 and $4.5 \mathrm{~mm}$ in diameter $(\mathrm{SA} 3, r=0.08, p$-value $=0.10)$.

\section{QTL mapping for root morphology and performance traits under low-P}

We mapped QTLs underlying P efficiency traits and found that the majority of the QTLs, primarily for PAE (9 out of 10) and PUE (9 out of 10), but also for PUTIL (although to a lesser extent) coincided with those detected for grain yield, with exception of the QTL on chromosome 5 for PUTIL (Additional file 3). This is consistent both with the much higher importance of PAE compared to PUTIL on PUE (Table 1) and with the strong association between grain yield and PAE/PUE (Additional file 2).

Although grain yield was the most informative trait for QTL detection, a PUTIL QTL on chromosome 5 may harbor genes underlying changes in $\mathrm{P}$ internal utilization and two chromosome 1 QTLs may jointly underlie PAE and PUTIL. As PUTIL was much less important than P acquisition efficiency for PUE, we thus focused primarily on the genetic mechanisms that enhance $\mathrm{P}$ acquisition efficiency via changes in root morphology and their role in increased grain yield on low-P soil.

We initially conducted single-trait QTL mapping with many different traits related to root morphology and sorghum performance under low-P conditions (Additional file 4). This analysis detected a total of 101 QTLs, with the favorable allele of 59 QTLs donated by the guinea parent, SC283, whereas the BR007 alleles increased phenotypic expression for 42 QTLs. Based on the correlation analyses between traits and on the single-trait QTL mapping results, we selected a subset of non-redundant and highly informative traits (i.e. traits 


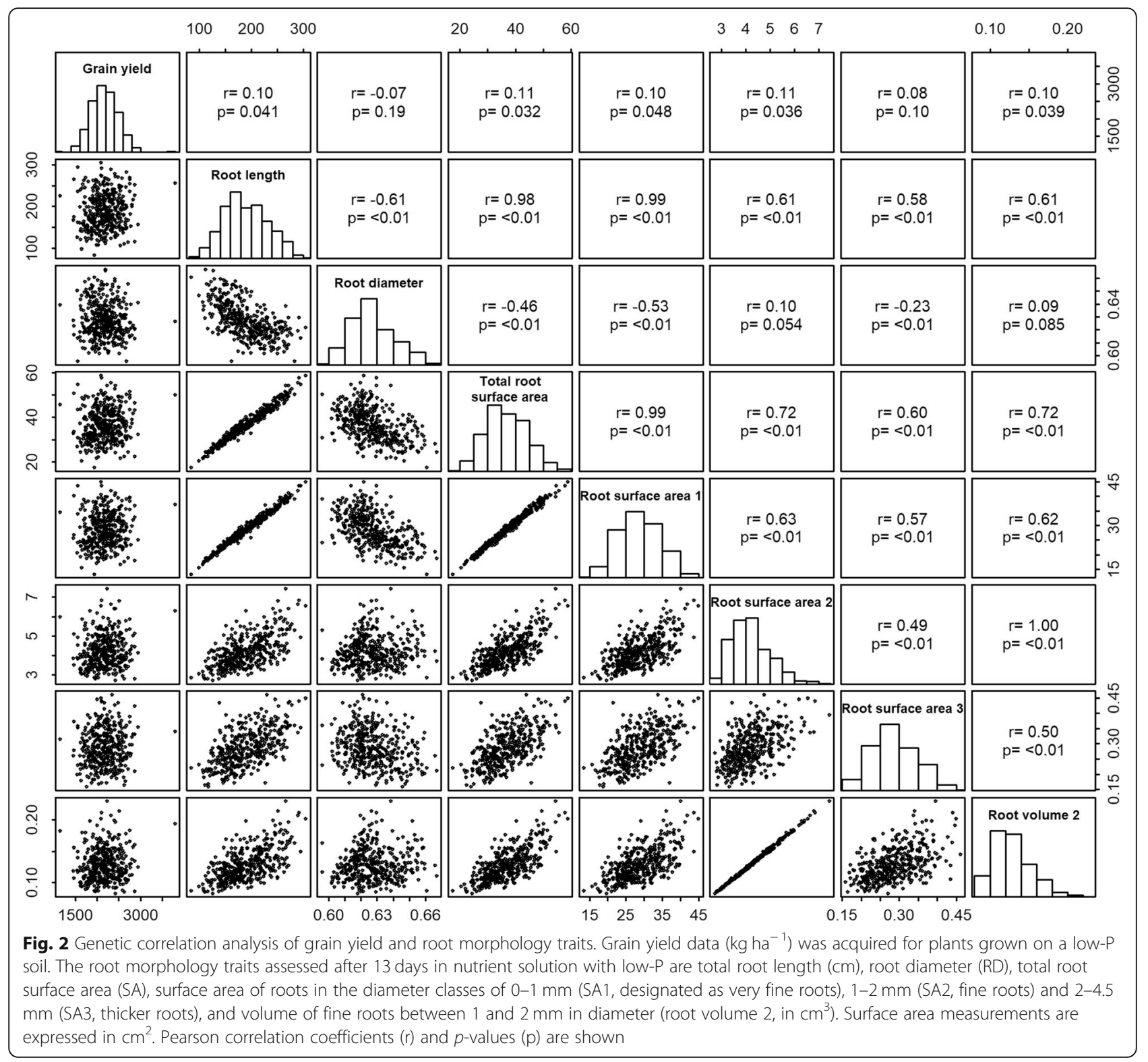

repeatedly associated with some QTLs) for multi-trait QTL mapping, focusing primarily on the most important $\mathrm{P}$ efficiency trait, namely grain yield under low-P availability in the soil (Fig. 3). P content in the grain (Pg), for example, was highly correlated with grain yield $(r=0.92)$ and we thus we only included grain yield and not Pg for multi-trait QTL mapping. The final set of traits used for multi-trait QTL mapping was comprised of grain yield (Gy), surface area of fine roots in the $1-2 \mathrm{~mm}$ diameter class (SA2) and root diameter (RD).

For the selected traits, the majority of the QTLs detected by single-trait QTL mapping (Fig. 3a-c) were also detected by multi-trait QTL mapping (Fig. 3d). Exceptions are the QTLs for SA2 on chromosomes 5, 7 and 9 and the Gy QTL on chromosome 8 and 10, which were not detected using multi-trait QTL mapping. Multi-trait mapping detected 14 QTLs (see Fig. 3a-c for single-trait mapping results) and revealed ten QTLs related to grain yield (Fig. 3d), within which one QTL was tightly linked to a root morphology QTL (Gy-3...SA2-3) and two were possibly pleiotropic with root morphology (Gy/SA2-3 and Gy/RD-7). For all of these QTLs, the favorable allele was donated by SC283 (Additional file 5). In contrast, the favorable alleles for five of the eight grain yield-specific QTLs were donated by BR007.

The different grain yield QTLs explained, in general, approximately 1 to $5 \%$ of the genetic variance and increased grain yield by $\sim 120 \mathrm{~kg} \mathrm{ha}^{-1}$ (Additional files 4 and 5), except for a Gy QTL at the end region of chromosome 9 (Gy-9). This QTL was detected for several different traits 


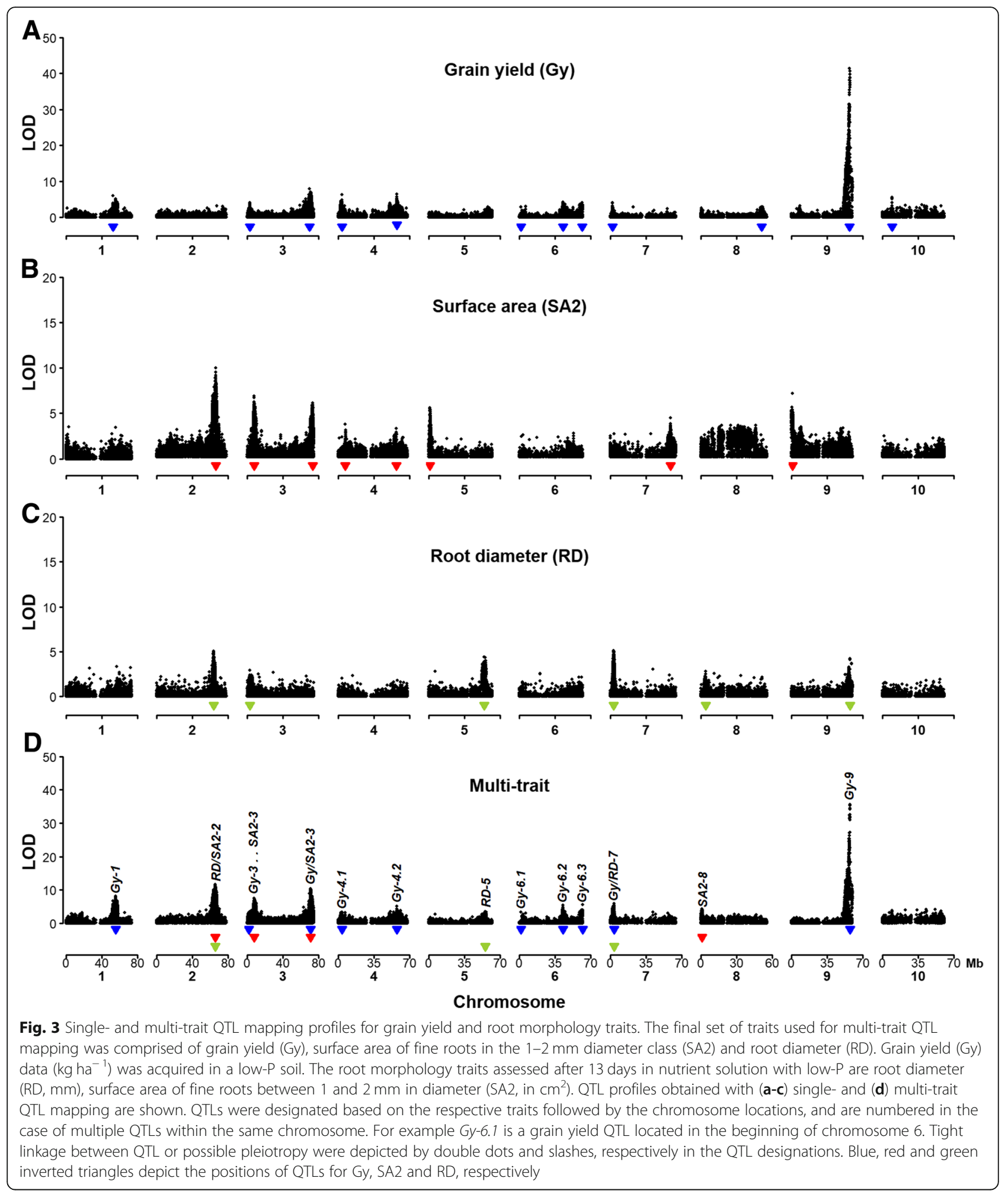

(Additional file 4), explained the largest proportion of the genetic variance ( $26 \%$, Additional file 4$)$, and was associated with the largest increase in grain yield, of $\sim 400 \mathrm{~kg} \mathrm{ha}^{-1}$, with the favorable allele donated by BR007.
Based on single-trait QTL analysis, all grain yield QTLs detected by multi-trait QTL mapping were co-located or were found near QTLs underlying P content and/or dry matter accumulation in hydroponics under low-P (Fig. 3, Additional file 4). The RD/SA2-2 
QTL (Additional file 5), which was the only root morphology QTL not associated with grain yield, co-located with QTLs for root dry matter accumulation, and shoot and root $\mathrm{P}$ content assessed in hydroponics via single-trait analyses (Additional file 4). Multi-trait QTL mapping provided insights into possible pleiotropic QTLs underlying changes in root system morphology and grain yield in the context of genes previously shown to be associated with those traits, such as sorghum homologs of the rice serine/threonine kinase, OSPSTOL1 [22]. The physical positions of the SbPSTOL1 genes and that of SbMATE, which confers sorghum Al tolerance [33], in the context of the QTL detected by multi-trait QTL mapping, are shown in Fig. 4. The QTLs Gy-3 and SA2-3 were in close physical proximity, between 5.38 and $0.46 \mathrm{Mb}$, respectively, from the PSTOL1 gene Sb03g006765 (Fig. 4a). At the end of chromosome 3, a cluster of four SbPSTOL1 genes were located $\sim 11 \mathrm{Mb}$ from the Gy/SA2-3 QTL and this QTL was only $80 \mathrm{~Kb}$ from SbMATE (Fig. 4b). Finally, the Gy/RD-7 QTL is located only $0.66 \mathrm{Mb}$ from the SbPSTOL1 gene, Sb07g002840 (Fig. 4c).

\section{Expression profile of SBPSTOL1 genes in the parent's root systems under low-P}

Multi-trait QTL mapping results indicated that the favorable alleles at QTLs either tightly linked or possibly pleiotropic with grain yield and root morphology on chromosomes 3 and 7, which were located in the vicinity of SbPSTOL1 genes, were consistently donated by SC283. Next, we assessed the expression profile of these SbPSTOL1 genes in roots of the RIL parents, BR007 and SC283, subjected to low-P conditions in hydroponics. Sb03g006765, located at the beginning of chromosome 3, and Sb03g031690, which is part of a SbPSTOL1 cluster at position $\sim 60 \mathrm{Mb}$ on chromosome 3 [22], were both more highly expressed in the roots of the guinea parent, SC283, in the low-P growth media (Fig. 5). In contrast, expression of $\mathrm{Sb07g002840}$ was higher in BR007 roots, which donates the inferior allele at the $G y / R D-7$ QTL.

\section{Discussion}

Low-P availability in the soil is a major factor that compromises food security in many developing countries in West Africa that rely on the sorghum crop for food production [2]. West Africa is the primary domestication center of the guinea race of sorghum [34], which is used therein as a pivotal staple food in areas with low soil fertility [35]. Thus, sorghum adaptation to soils with low-P availability becomes critical for food security $[5,35]$.

Our QTL mapping study emphasized the complex nature of traits related to $\mathrm{P}$ efficiency in sorghum, with favorable alleles donated by both parents in rather equal proportions. However, the observed slight overrepresentation of superior QTL alleles derived from the guinea race parent, SC283, may not be coincidental, reflecting local adaptation of guinea sorghums to poor soil fertility and acid soils in West Africa [2].

\section{QTLs for root morphology coincide with grain yield QTL under low-P availability}

The root system of monocotyledonous crop plants consists of one or more seminal roots that originate from the seed embryo after germination, and crown roots that emerge later from nodes along the stem [36]. Increased root surface area, which can be achieved via enhanced lateral root branching, can enhance P uptake and plant growth [37]. Among the ten grain yield QTL that were detected by multi-trait mapping, three were either tightly linked (one QTL) or possibly pleiotropic (two QTL) with root morphology traits. Those are: 1) the grain yield QTL, Gy-3 and the QTL for surface area of fine roots, SA2-3 at the beginning of chromosome 3, which are only $\sim 6 \mathrm{Mb}$ apart; 2) the pleiotropic Gy/SA2-3 QTL at position $\sim 71 \mathrm{Mb}$ on chromosome 3 ; and 3 ) the Gy/RD-7 QTL at $3.6 \mathrm{Mb}$ on chromosome 7 (Fig. 3d). Thus, our multi-trait QTL mapping approach established an important role for root system morphology as an entry point for molecular breeding strategies targeting enhanced $\mathrm{P}$ uptake and grain yield under low-P availability in the soil.

\section{Specific changes in root morphology are likely important for P efficiency}

The grain yield QTLs that are possibly determined by changes in root surface area seem to be more specific to roots between 1 and $2 \mathrm{~mm}$ (SA2) in diameter than to the very fine roots between 0 and $1 \mathrm{~mm}$ (SA1) or thicker roots (2-4.5 $\mathrm{mm}, \mathrm{SA} 3)$. Via single-trait mapping, a QTL for SA2 (and not for other root diameter classes) was found at the beginning of chromosome 3, tightly linked to a Gy QTL, whereas the grain yield/surface area QTL at the end of chromosome 3 was near SA2 and SA3 QTL. A total surface area (SA) QTL was also found at the end of chromosome 3 , but this is expected as total surface area, which is highly correlated with SA1, largely represents the sum of surface area of roots in all diameter classes. Importantly, eight QTLs in total were detected for surface area of fine roots via single-trait mapping, whereas only four and two QTLs were detected for total surface area (that is highly correlated with surface area of very fine roots, $r=0.99$ ) and for surface area of thicker roots, respectively. Very thick roots are not expected to play a major role in nutrient uptake, as plant species with a majority of fine roots in their root systems tend to optimize the ratio between root surface area available for uptake and root weight, reflecting a reduced carbon cost for root biomass formation [38]. 


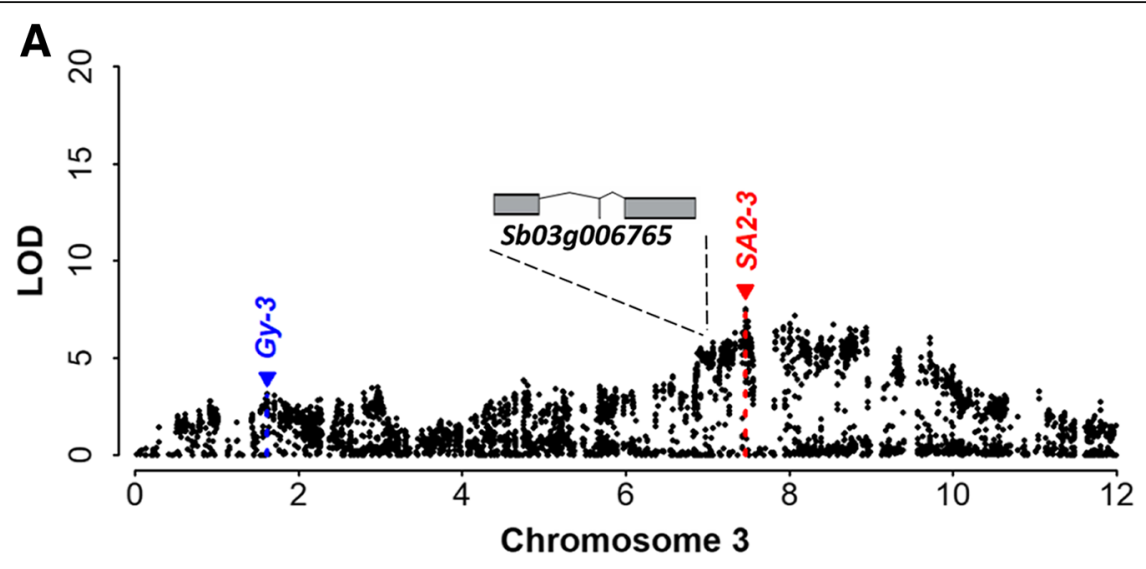

B

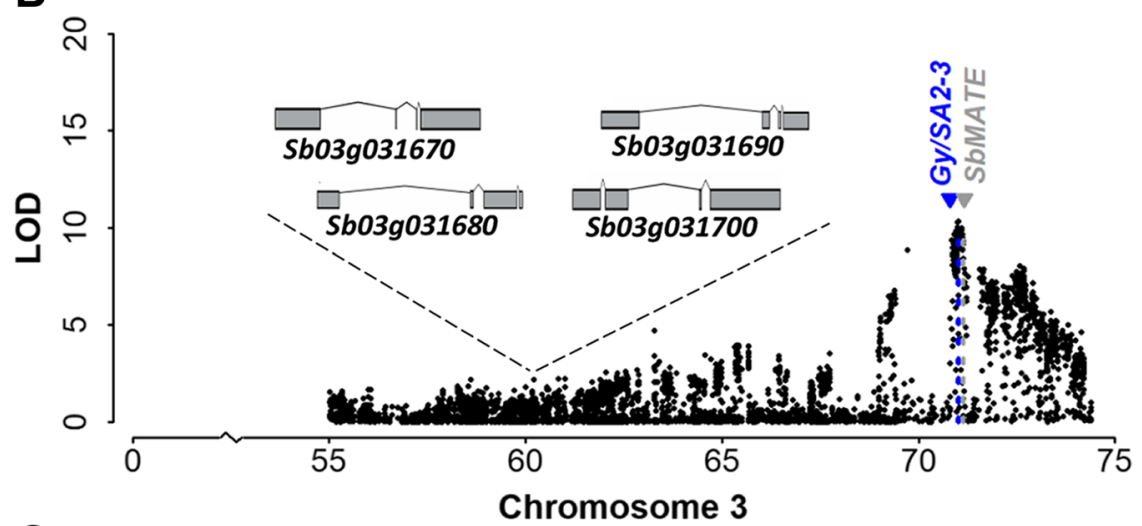

C

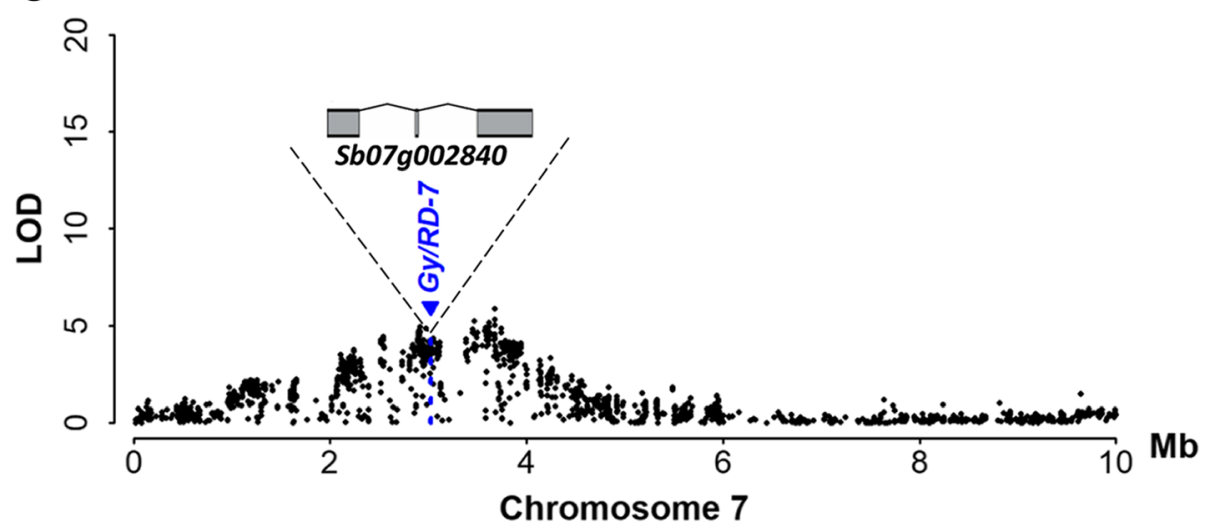

Fig. 4 Physical positions of SbPSTOL1 genes in the context of the QTL regions detected by multi-trait QTL mapping (Fig. 3d). The root morphology traits assessed after 13 days in nutrient solution with low-P are root diameter (RD, $\mathrm{mm}$ ) and surface area of fine roots between 1 and $2 \mathrm{~mm}$ in diameter $\left(\mathrm{SA} 2\right.$, in $\mathrm{cm}^{2}$ ). Possible pleiotropy between Gy (grain yield), SA2 and RD QTL, when detected, were depicted by slashes in the QTL designations. Physical positions and gene models for the SbPSTOL1 genes (https://phytozome.jgi.doe.gov/, v1.4 of the sorghum genome), a S603g006765, b the SbPSTOL1 cluster including S603g031690 and (c) Sb07g002840 are shown

It is generally thought that the finer the roots, the better the root system can mine the soil for diffusion-limited nutrients, like the phosphate anion on tropical soils. However, although fine roots are the key factor for uptake, particularly for nutrients with very low mobility in tropical soils such as $\mathrm{P}$, our QTL data interestingly suggest there is a trade-off between decreased root diameter and enhanced $\mathrm{P}$ uptake. This can be expected as decreased root diameter, beyond a given threshold may, for example, limit root penetration through the soil [38] and, possibly, lead to less root longevity [39]. 


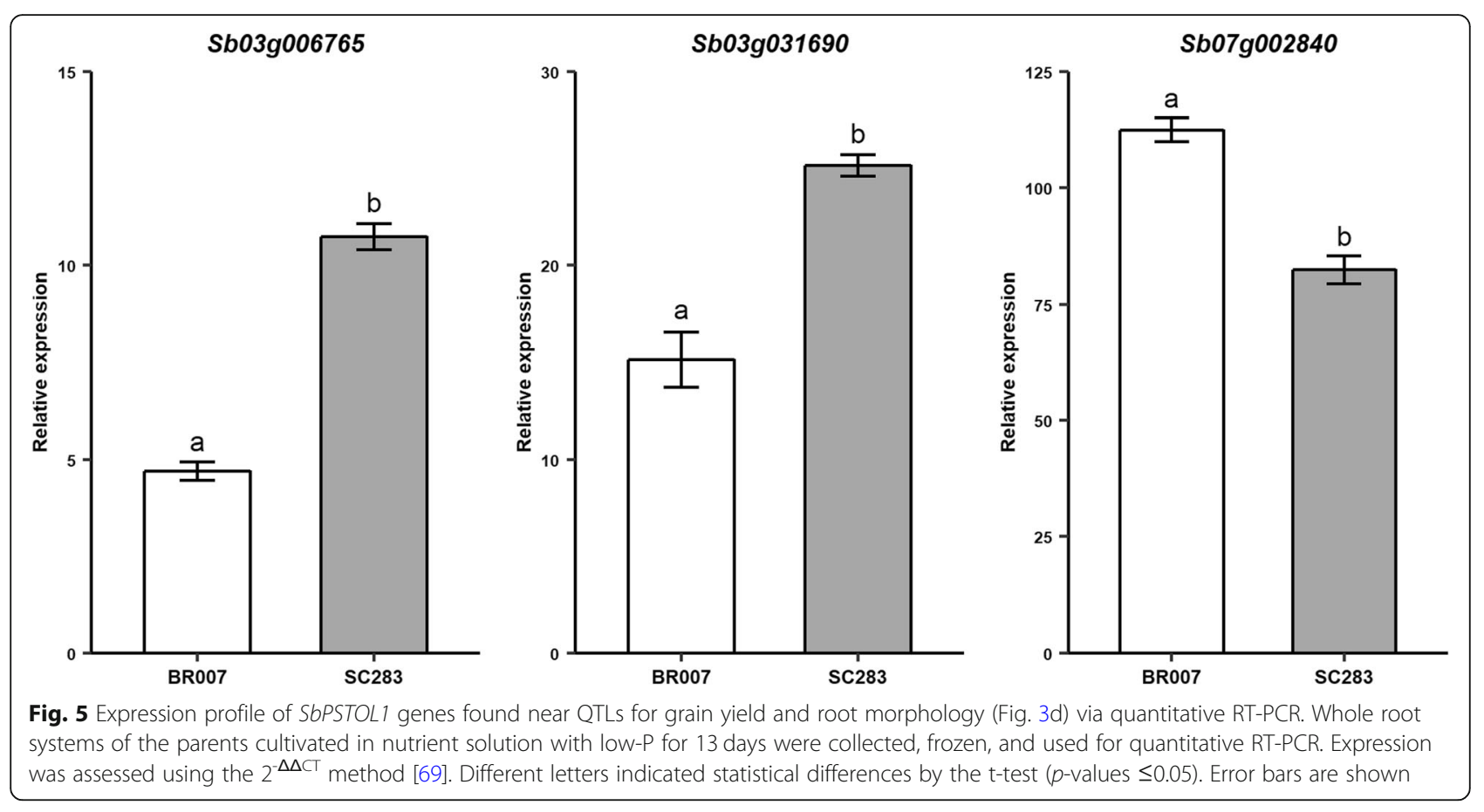

\section{SbPSTOL1 genes possibly underlie QTLs for root morphology and grain yield}

All three root morphology QTL that were found to be either tightly linked or pleiotropic with grain yield are located in the vicinity of sorghum homologs of the rice serine/threonine kinase, OSPSTOL1, which was previously found to enhance early root growth and grain yield in rice under low-P availability [21].

Based on multi-trait mapping, two QTLs underlying grain yield and root surface area, Gy-3 and $S A 2-3$, were found on chromosome 3 at positions 1.6 and $7.4 \mathrm{Mb}$, respectively. Those QTLs are only $\sim 6 \mathrm{Mb}$ apart and are physically very close to the SbPSTOL1 gene, Sb03g006765, at position $7 \mathrm{Mb}$. A possible pleiotropic QTL, simultaneously underlying SA2 and Gy (Gy/SA2-3), was found approximately $\sim 11 \mathrm{Mb}$ from a SbPSTOL1 cluster at position $\sim 60 \mathrm{Mb}$ on chromosome 3 . The favorable alleles both at the SA2 and Gy QTLs near Sb03g006765 and at the possible $G y / S A 2-3$ pleiotropic QTL at position $71 \mathrm{Mb}$ are derived from the guinea parent, SC283. Although BR007 tended to show greater root surface area compared to SC283, this is due to the prevalence in BR007 of very fine roots, between 0 and $1 \mathrm{~mm}$ in diameter (Fig. 1). Compared to BR007, SC283, which donates the positive alleles for the Gy and SA2 QTLs in the vicinity of SbPSTOL1 genes, has about twice the proportion of fine roots between 1 and $2 \mathrm{~mm}$ in diameter, whose surface area gives rise to both SA2 QTL on chromosome 3. Finally, both $S b 03 g 006765$ and $S b 03 g 031690$ (that is part of a SbPSTOL1 cluster at position $\sim 60 \mathrm{Mb}$ ), exhibited significantly higher expression in response to low-P growth conditions specifically in SC283 roots, when compared to BR007, which is in agreement with SC283 donating SbPSTOL1 alleles that enhance the surface area of fine roots at the respective chromosome 3 QTL.

Previously, single nucleotide polymorphism (SNP) loci within the SbPSTOL1 gene Sb03g006765, and in the SbPSTOL1 genes present in the gene cluster at position $\sim 60 \mathrm{Mb}$, were associated both with variation in root surface area and sorghum performance under low-P [22]. This suggests that the grain yield QTL on chromosome 3 results, at least in part, from enhanced surface area conferred by SbPSTOL1 genes. However, the major $\mathrm{Al}$ tolerance gene, SbMATE, is located at position $71 \mathrm{Mb}$ on the same chromosome, and thus is closer to the pleiotropic Gy/SA2-3 QTL in the region (Fig. 4). SbMATE has been shown to contribute to grain yield under low-P conditions, possibly via citrate-based enhanced mobilization of $\mathrm{P}$ that is bound to the soil clays [5], or simply as an indirect effect of enhanced root development under Al toxicity in the subsoil [15]. Thus, we cannot rule out that SbMATE is responsible for some of the yield advantage that gives rise to the grain yield QTL at the end of sorghum chromosome 3.

We previously reported that allelic variation at the SbPSTOL1 gene, Sb07g002840, influences root diameter, biomass accumulation and $\mathrm{P}$ uptake, although associations with grain yield were not found using a sorghum association panel [22]. A pleiotropic QTL underlying both Gy and RD was found only $\sim 0.6 \mathrm{Mb}$

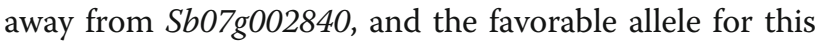
$G y / R D-7$ QTL was donated by SC283. It is interesting to 
note that SC283 exhibits overall a larger root diameter compared to BR007, which is in agreement with the SC283 origin of the favorable allele at the $G y / R D-7$ QTL. In barley subjected to low-P conditions, based on the effects of co-localized QTLs, larger root diameter was related to higher grain yield [40], which is consistent with our results with $S b 07 g 002840$. A positive relationship has been reported between the size of the apical meristem (reflected by the apical diameter) and important characteristics such as the elongation rate, growth duration and gravitropism [38], which could lead to enhanced performance under low-P conditions. It is thus possible that the slight increases in root diameter elicited by $S 607 g 002840$ lead to an increase in the surface area of laterals that are still fine, generating more physically robust roots without substantial carbon cost. Hence, these roots would be more efficient to optimize $\mathrm{P}$ mining in the soil, leading to enhanced $\mathrm{P}$ uptake and grain yield under soil low-P availability. Unlike the SbPSTOL1 genes on chromosome 3, root Sb07g002840 expression is lower in SC283 compared to BR007. This could suggest an allele-specific repressor effect of Sb07g002840 on root diameter, with lower expression of the SC283 allele of Sb07g002840, leading to a slight increase in root diameter.

\section{Synteny analysis in sorghum and maize supports a role for PSTOL1 genes in root morphology and reveals other genes possibly involved in $P$ efficiency}

We compared the positions of the grain yield QTL detected in sorghum by multi-trait QTL mapping with QTLs related to root morphology and P efficiency reported in the closely related species, maize. The summary shown in Additional file 6 was based primarily on a QTL mapping study that included the same traits used in our sorghum RIL population [41] and in a comprehensive meta-analysis of QTLs related to low-P tolerance in maize, which defined 23 consensus QTL (cQTL, [42]).

The maize root morphology QTLs, qMulti3.04, $q R L 8.05$ and $q R D 4.05$, harbor maize homologs of Sb03g006765, Sb03g031690, and Sb07g002840, respectively (the SbPSTOL1 genes at chromosomes 3 and 7 that are near grain and root morphology QTLs, Fig. 4), in regions that are syntenic between maize and sorghum (Additional file 6). Consistent with our findings that Sb07g002840 influences root diameter, qRD4.05 is also associated with changes in root diameter in maize. Four homologs of OsPSTOL1 were found in maize cQTL3-1 at bin 3.04 [42], which overlaps with qMulti3.04 [41] that is associated with multiple root morphology traits. In this region, the maize PSTOL1-like gene, GRMZM2G412760, is closely related to Sb03g006765. In conjunction with the presence of a functional PSTOL1 protein in rice (OsPSTOL1, [21]), this suggests that the PSTOL1 function in modulating root morphology is rather ancient, predating the divergence between maize, sorghum and rice.

This analysis also suggests possible functions for grain yield QTL that are apparently unrelated to root morphology in sorghum. Previously, we detected a major QTL for plant height and flowering time at the end region of sorghum chromosome 9 [43], which coincides with the QTL underlying multiple traits that was found in the present study. The ubiquitin-conjugating enzyme UBC24, encoded by phosphate 2 (PHO2), which is a major player in $\mathrm{P}$ homeostasis and plant responses to $P$ deficiency [44], has been recently implicated in tolerance to low-P in maize [45]. We found a highly similar PHO2 homolog at position $\sim 57 \mathrm{Mb}$ on sorghum chromosome 9, which closely overlaps with multiple QTLs related to root morphology and many other traits, including grain yield (Additional file 4 and Fig. 3). GRMZM2G381709, a maize homolog of PHO2, is also located in a syntenic position of the maize genome, near a cQTL (cQTL6-2) for low-P tolerance in maize defined by meta-analysis (Additional file 6).

Sorghum homologs of the auxin transporters, PIN1 and PIN6, are found near the grain yield QTL at position $\sim 58$ $\mathrm{Mb}$ on sorghum chromosome 4 (Fig. 3). A related PIN protein in maize is found near another QTL for tolerance to low-P conditions in maize, $c Q T L 5-5$ (Additional file 6). PIN genes that encode auxin transporters have been implicated in root architecture changes involving lateral roots under low-P in wheat [46] and may play a significant role in sorghum and maize P efficiency. On chromosome 6, a sorghum homolog of the $\mathrm{Al}$ tolerance gene, ALMT1, which encodes a root malate efflux transporter and has been recently reported to modulate root growth in response to low-P [30], is found at position $\sim 44 \mathrm{Mb}$, thus near the grain yield QTL at position $42.5 \mathrm{Mb}$ (Fig. 3 and Additional file 4). In maize, the consensus QTL, cQTL10-1 [42], is also found near a maize homolog of $A L M T 1$, suggesting a role for ALMT1 on $\mathrm{P}$ efficiency in both maize and sorghum. As with SbMATE, it is also possible that root malate release via ALMT1 is involved in solubilizing $P$ that is fixed on the surface of $\mathrm{Fe}$ and $\mathrm{Al}$ oxide minerals in the soil, making them bioavailable for root uptake.

\section{Conclusions}

Phosphorus acquisition efficiency was the major component of P efficiency for sorghum cultivated under low-P availability in the soil and grain yield was highly correlated with both traits. Although our findings emphasize root system morphology as a major target for molecular approaches aimed at developing $\mathrm{P}$ efficient sorghum cultivars, other distinct mechanisms may also play a 
significant role in sorghum performance on low-P soils via enhanced $\mathrm{P}$ acquisition. The molecular determinants of such mechanisms, along with SbPSTOL1 genes, should power novel, gene-based molecular breeding strategies to enhance food security in tropical regions with low-P availability.

\section{Methods}

\section{Genetic material}

A population composed of 396 recombinant inbred lines (RILs, $\mathrm{F}_{10: 11}$ ), derived from a cross between the sorghum lines, BR007 and SC283, was developed by single-seed descent [47] at Embrapa Maize and Sorghum (Sete Lagoas - MG, Brazil). Both BR007 (Redbine-type) and SC283 (sorghum converted guinea) were introduced into the Embrapa breeding program in 1972 from the Purdue Breeding Program (West Lafayette - IN, US). BR007 is Al sensitive whereas SC283 is highly tolerant to $\mathrm{Al}$ toxicity [33]. Previous studies indicated that, while SC283 has higher grain yield in a soil with low-P availability compared to BR007, the grain yield increase in BR007 in response to adequate $\mathrm{P}$ supply is in turn higher than in SC283 [48].

\section{Phenotyping for low-P in field conditions}

Four field experiments were conducted at the experimental station of Embrapa Maize and Sorghum in Sete Lagoas, State of Minas Gerais, Brazil, during the summer season of 2012-2013. The experimental site is a clay and highly weathered tropical soil, with low fertility in natural conditions, low $\mathrm{pH}, \mathrm{Al}$ toxicity and low-P. Soil $\mathrm{P}$ (Mehlich 1) varied from 1 to $6 \mathrm{ppm}$ between 0 and $20 \mathrm{~cm}$ of soil depth, and from 1 to $4 \mathrm{ppm}$ at the sub-superficial soil layer $(20-40 \mathrm{~cm})$. The minimum and maximum content of available $\mathrm{P}$ in the soil (Psoil) was $5.88 \mathrm{~kg} \mathrm{ha}^{-1}$ and $19.79 \mathrm{~kg} \mathrm{ha}^{-1}$.

Each experiment was arranged as a $12 \times 10$ alpha lattice design, with three complete replicates and ten incomplete blocks per replicate. Each block contained 12 plots, within which ten RILs (regular treatments) and the two parents (common checks) were allocated. Each plot consisted of a three-meter row, with $0.45 \mathrm{~m}$ between rows and 8 plants $\mathrm{m}^{-1}$. Fertilization consisted of $150 \mathrm{~kg}$ $\mathrm{ha}^{-1}$ of 20-00-20 (NPK) at sowing and $200 \mathrm{~kg} \mathrm{ha}^{-1}$ of urea applied 30 days after sowing.

Grain yield (Gy, $\mathrm{kg} \mathrm{ha}^{-1}$ ), flowering time (FT, days), plant height $(\mathrm{PH}, \mathrm{cm})$, phosphorus content in the plant (leaves and stems - Pp, $\mathrm{kg} \mathrm{ha}^{-1}$ ) and phosphorus content in the grain $\left(\mathrm{Pg}, \mathrm{kg} \mathrm{ha}^{-1}\right)$ were evaluated. For P measurements, samples of plant tissues and grains were collected in each plot, weighted and then dried at $65^{\circ} \mathrm{C}$ to constant weight. Dry plant tissues and grains were then weighted, grounded and homogenized. Twenty gram - subsamples were used to determine $\mathrm{P}$ concentration and total $\mathrm{P}$ content $(\mathrm{Pt})$, using inductively-coupled argon plasma emission spectrometry.

The phosphorus efficiency indexes were calculated according to the methodology proposed by Moll et al. [32], where: 1) phosphorus use efficiency (PUE) is equal to the product between phosphorus acquisition efficiency (PAE) and phosphorus internal utilization efficiency (PUTIL); 2) PAE is the total phosphorus content $(\mathrm{Pt}=\mathrm{Pp}$, $\mathrm{P}$ content in the plant $+\mathrm{Pg}, \mathrm{P}$ content in the grain) divided by P content available in the soil; 3) PUTIL is Gy divided by Pt.

\section{Root system phenotyping in low-P conditions}

Root morphology traits were assessed in nutrient solution as described by de Sousa et al. [49] and Hufnagel et al. [22], using a randomized block design with three replicates. Seeds were surface-sterilized using sodium hypochlorite $(5 \%)$, washed with distilled water and placed in moistened paper rolls. After 4 days, uniform seedlings were transferred to moistened blotting papers and placed into paper pouches $(24 \times 33 \times 0.02 \mathrm{~cm})$ as described by Hund et al. [50].

Each experimental unit consisted of one pouch, with three plants per pouch, whose bottom $(3 \mathrm{~cm})$ was immersed in containers filled with 51 of the nutrient solution described in [51], with pH 5.65 and a P concentration of $2.5 \mu \mathrm{M}$. The containers were kept in a growth chamber with $27^{\circ} \mathrm{C}$ day and $20^{\circ} \mathrm{C}$ night temperatures and a 12-h photoperiod, under continuous aeration for 13 days.

After 13 days, root images were acquired using a digital camera Nikon D300S SLR. Images were then analyzed using both the RootReader2D (http:// www.plantmineralnutrition.net/software/rootreader2d/) and WinRhizo (http://www.regent.qc.ca/) software. The following traits were measured: root length (RL $\mathrm{cm})$; root diameter (RD - mm); total root surface area $\left(\mathrm{SA}-\mathrm{cm}^{2}\right)$; surface area of very fine roots between 0 and $1 \mathrm{~mm}$ in diameter (SA1 $\left.-\mathrm{cm}^{2}\right)$; surface area of fine roots between 1 and $2 \mathrm{~mm}$ in diameter $\left(\mathrm{SA} 2-\mathrm{cm}^{2}\right.$ ); surface area of thicker roots between 2 and $4.5 \mathrm{~mm}$ in diameter $\left(\mathrm{SA} 3-\mathrm{cm}^{2}\right)$; root volume $\left(\mathrm{RV}-\mathrm{cm}^{3}\right)$ and volume of fine roots between 1 and $2 \mathrm{~mm}$ in diameter $\left(\mathrm{V} 2-\mathrm{cm}^{3}\right)$. Shoot dry matter (SDM) and root dry matter (RDM), phosphorus content in the shoot (Ps) and phosphorus content in the root (Pr) (in grams) were also measured.

\section{Phenotypic analyses}

Traits assessed in field and hydroponic experiments were analyzed using mixed models. For field experiments, the following model was used: 


$$
y_{i j k l}=\mu+E_{j}+R_{k(j)}+B_{l(k j)}+G_{i}+\varepsilon_{i j k l}
$$

$y_{i j k l}$ is the phenotypic value of individual $i$ in the block $l$ of the $k^{\text {th }}$ replicate, within the experiment $j ; \mu$ is the overall mean; and $G_{i}$ is the genetic effect of individual $i$, which can be defined as:

$$
G_{i}=\left\{\begin{array}{c}
g_{i} i=1, \ldots, n_{g} \\
t_{i} i=n_{g}+1, \ldots, n_{g}+n_{c}
\end{array}\right.
$$

$g_{i}$ is the random effect of RIL $i, n_{g}$ is the total number of RILs; $t_{i}$ is the fixed effect of check $i$; and $n_{c}$ is the total number of checks; $E_{j}$ is the fixed effect of the $j^{\text {th }}$ experiment $(j=1, \ldots, 4) ; R_{k(j)}$ is the fixed effect of replicate $k(k=1, \ldots, 3)$ in experiment $j ; B_{l(k j)}$ is the random effect of block $l(l=1, \ldots, 10)$ in the replicate $k$, within the experiment $j$; and $\boldsymbol{\varepsilon}=\left(\varepsilon_{1111}, \varepsilon_{2111}, \ldots, \varepsilon_{I J K L}\right)^{\prime}$ is a $N_{o b s} \times 1$ residual random vector assumed to be normally distributed with mean zero and variance $\sigma_{\varepsilon}^{2}$, in which $N_{o b s}$ is the total number of observations.

The model used for analyzing the hydroponic experiments was:

$$
y_{i j}=\mu+B_{j}+g_{i}+\varepsilon_{i j}
$$

where $y_{i j}$ is the phenotypic value of the RIL $i(i=1, \ldots$, $n_{g}$ ) in the block $j ; \mu$ is the overall mean; $g_{i}$ is the random genetic effect of RIL $i ; B_{j}$ is the fixed effect of block $j$ ( $j$ $=1, \ldots, 3)$; and $\boldsymbol{\varepsilon}=\left(\varepsilon_{11}, \varepsilon_{21}, \ldots, \varepsilon_{I J}\right)^{\prime}$ is a $N_{o b s} \times 1$ residual random vector assumed to be normally distributed with mean zero and variance $\sigma_{\varepsilon}^{2}$. Fixed and random effects were tested using the Wald statistics [52] and the likelihood ratio test (LRT, [53]) respectively, considering a 5\% significance level $(\alpha)$.

For both statistical models, the genetic effect of RIL was first taken as random for estimating the genetic variance component $\left(\sigma_{g}^{2}\right)$ via restricted maximum likelihood (REML), and the heritability coefficient of each trait. The effect of RIL was then considered as fixed for estimating the adjusted means using best linear unbiased estimators (BLUEs). All the mixed models analyses were performed using the GenStat software (v.17.1.0) [54].

Trait heritabilities were estimated as proposed by Cullis et al. [55], called generalized heritabilities, using:

$$
h^{2}=1-\frac{\bar{v} B L U P}{2 \sigma_{g}^{2}}
$$

where $\bar{v} B L U P$ is the average variance of the difference between two best linear unbiased predictions (BLUPs). Person's correlation coefficients [56] were estimated based on the adjusted means of genotypes for traits assessed in the field and in the hydroponic experiments, using the package Hmic [57] in R [58].

\section{SNP markers}

Genomic DNA was isolated from approximately $500 \mathrm{mg}$ of leaf tissue (eight plants per accession, i.e. RILs and their parents) as described by Saghai-Maroof et al. [59]. DNA samples were genotyped by sequencing according to Elshire et al. [60]. Reads were aligned to the version 1.4 of sorghum reference genome using Burrows-Wheeler Aligner program (BWA - [61]), and the SNP calling was performed using the GBS pipeline [62] implemented in the TASSEL software [63]. Missing genotypes were imputed using the NPUTE software [64]. Then, SNP data were filtered for $40 \%$ of minor allele frequency (MAF).

\section{QTL mapping}

The final set of traits used for multi-trait QTL mapping was comprised of grain yield (Gy), surface area of fine roots in the 1-2 mm diameter class (SA2) and root diameter (RD). Multi-trait QTL mapping analysis was performed according to the procedures described in Silva et al. [65] implemented in R. For that, a multi-locus QTL mapping procedure was considered, using the Haley \& Knott regression [66] and the following linear model:

$$
y_{t i}=\mu_{t}+\sum_{r=1}^{m} a_{t r} x_{i r}+\varepsilon_{t i}
$$

where $\boldsymbol{y}_{t i}$ is the adjusted mean of RIL $i\left(i=1, \ldots, n_{g}\right)$ for trait $t(t=1, \ldots, T) ; \mu_{t}$ is the intercept for each trait; $a_{t r}$ is the $r^{\text {th }}$ QTL main effect on trait $t ; x_{i r}$ represents the genotype of RIL $i$ for the SNP marker $r\left(r=1, \ldots, n_{M}\right)$, being $n_{M}$ the total number of markers; $x_{i r}$ assumed values equal to 0 or 2 for RILs with homozygous genotypes for the allele donated by BR007B or SC283, respectively; and $\boldsymbol{\varepsilon}_{i}=\left(\varepsilon_{1 i}, \varepsilon_{2 i}, \ldots, \varepsilon_{T i}\right)^{\prime}$ is a $T \times 1$ random vector assumed to be independent and identically distributed according to a multivariate normal distribution with mean vector zero and positive definite symmetric variance-covariance matrix $\Sigma_{\varepsilon}$, i.e. $\boldsymbol{\varepsilon}_{i} \sim M V N\left(0, \Sigma_{\varepsilon}\right)$. Single-trait QTL mapping analyses were performed for each trait, using the above model $(t=1$ gives an univariate regression model).

Multiple QTL models were built based on a forwardselection procedure, testing the significance of a putative QTL main effect at each SNP position along the genome. Significance of QTLs main effects were tested using the Score Statistic [67], considering a 10\% significance level $(\alpha)$. According to simulations performed by Silva et al. [65], this significance level maximized the QTL detection power and kept the false discovery rate (i.e. the proportion of spurious QTLs) within an acceptable level.

QTL positions were refined after the inclusion of every new QTL in the model, until no more significant QTL 
main effects were found. Finally, non-significant QTL effects were removed from the model in a backwardelimination procedure, such as proposed in the seemingly unrelated regression coefficients method [68], considering a $1 \%$ significance level.

\section{Quantitative analysis of SbPSTOL1 gene expression}

Sorghum seedlings were grown in a modified Magnavaca nutrient solution [51] containing a low-P concentration $(2.5 \mu \mathrm{M} \mathrm{P})$, as described in the section Root system phenotyping in low-P conditions. The experiment was set up in randomized block design with three replicates and three seedlings per experimental unit (paper pouch), giving a total of nine biological replicates per genotype. After 13 days in nutrient solution, the expression profiles of the SbPSTOL1-like genes (Sb03g006765, Sb03g031690, and $S b 07 g 002840$ ) were assessed in the roots of the RIL parents, BR007 and SC283. Total RNA was isolated from bulked root tissues (nine roots per bulk), using the SV Total RNA Isolation System kit (Promega Corporation, Madison, WI, USA), according to the manufacturer's instructions. Total RNA $(1 \mu \mathrm{g})$ was used for cDNA synthesis using the High Capacity cDNA Reverse Transcription kit (Applied Biosystems, Foster City, CA, USA). Transcripts were quantified by quantitative real-time PCR (qPCR-RT), using SYBR Green technology with the ABI Prism 7500 Fast System (Applied Biosystems, Foster City, CA, USA).

Transcript relative quantification was performed with $20 \mathrm{ng}$ cDNA samples and $0.02 \mathrm{ng}$ for the endogenous constitutive control ( $18 \mathrm{~s}$ rRNA). Primers were designed for SbPSTOL1 and $18 \mathrm{~s} r R N A$ sorghum genes using the PrimerQuest tool (https://www.idtdna.com/PrimerQuest/) (Additional file 7). Calculation of relative gene expressions were performed using the $2^{-\Delta \Delta C T}$ method [69], with three technical replicates.

\section{Additional files}

Additional file 1: Descriptive statistics and variance components for traits assessed in low-P conditions. (field and hydroponics). (DOCX $27 \mathrm{~kb}$ )

Additional file 2: Correlations and $p$-values among all traits assessed in low-P conditions. (field and hydroponics). (DOCX $30 \mathrm{~kb}$ )

Additional file 3: Single-trait QTL mapping profiles for grain yield (Gy), phosphorus use efficiency (PUE), phosphorus acquisition efficiency (PAE) and phosphorus internal utilization efficiency (PUTIL). Blue, light blue, pink and yellow inverted triangles depict the positions of QTLs for Gy, PUE, PAE and PUTIL respectively. (TIF $127 \mathrm{~kb}$ )

Additional file 4: Detailed information and confidence interval of the QTLs detected by single-trait QTL mapping. (Sheets "Single-trait values" and "Confidence Interval". (XLSX 33 kb)

Additional file 5: Detailed information of the QTLs detected by multi-trait QTL mapping. (DOCX 24 kb)

Additional file 6: Synteny between sorghum, Arabidopsis and maize for the main QTLs detected in this study. (XLSX $55 \mathrm{~kb}$ )

Additional file 7: Primers used for qPCR-RT assays. (DOCX 14 kb)

\section{Abbreviations}

Al: Aluminum; ALMT1: Aluminum-activated malate transporter in wheat: ALS3: Aluminum sensitive 3 (ABC-like transporter); Alt $t_{S B}$ : Aluminum tolerance locus in Sorghum bicolor; AtSTOP1: Sensitive to proton rhizotoxicity in Arabidopsis; BLUE: Best linear unbiased estimation; BLUP: Best linear unbiased predictions; BWA: Burrows-wheeler aligner program; DM: Dry matter; E2: Ubiquitin-conjugating enzyme; FT: Flowering time; GBS: Genotyping by sequencing; Gy: Grain yield; LRT: Likelihood rate test; MAF: Minimum allele frequency; Mb: Mega base pairs; OsPSTOL 1: Phosphorus starvation tolerance 1 in rice; P: Phosphorus; PAE: Phosphorus use efficiency; Pg: Phosphorus content in grain; PH: Plant height; PHO2: Phosphate 2; Pp: Phosphorus content in the plant (leaves and stem); Pr: Phosphorus content in root tissues; Ps: Phosphorus content in the shoot;

Psoil: Phosphorus content available in the soil; Pt: Total phosphorus content; PUE: Phosphorus use efficiency; PUTIL: Phosphorus internal utilization efficiency; QTL: Quantitative trait locus; r: Correlation coefficient; RD: Root diameter; RDM: Root dry matter; REML: Restricted maximum likelihood; RIL: Recombinant inbreed line; RL: Root length; RV: Root volume; SA: Total root surface area; SA1: Surface area of very fine roots between 0 and $1 \mathrm{~mm}$ in diameter; SA2: Surface area of fine roots between 1 and $2 \mathrm{~mm}$ in diameter; SA3: Surface area of thicker roots between 2 and $4.5 \mathrm{~mm}$ in diameter; SBMATE: Multidrug and toxic compound extrusion in Sorghum bicolor; SbPSTOL 1: Phosphorus starvation tolerance1 in Sorghum bicolor; SDM: Shoot dry matter; SNP: Single nucleotide polymorphism; SRL: Specific root length; UBC24: Ubiquitin-conjugating 24 enzyme; V2: Volume of fine roots between 1 and $2 \mathrm{~mm}$ in diameter

\section{Acknowledgements \\ We thank all staff and trainees of Embrapa Maize and Sorghum that indirectly collaborated in the execution of this work.}

\section{Funding}

We acknowledge grants from the CGIAR Generation Challenge Program, the Embrapa Macroprogram, the Fundação de Amparo a Pesquisa do Estado de Minas Gerais (FAPEMIG) and the National Council for Scientific and

Technological Development (CNPq). The funding body had no role in the design of the study and collection, analysis, and interpretation of data and in writing the manuscript.

\section{Availability of data and materials}

The datasets used and/or analyzed during the current study are available from the corresponding author on reasonable request.

\section{Authors' contributions}

Conceived, supervised the study, contributed to manuscript writing and revision: JVM. Performed experiments, analyzed the data and contributed to manuscript writing: KCB. Contributed to sorghum phenotyping: CBM, SMS, GCJ, RES. Designed the statistical framework, contributed to data analysis and interpretation: MMP, LCS. Conducted expression profiling: LSM and BAB. Synteny analyses and manuscript revision: LVK and CTG. Revised the paper: PCSC. All authors read and approved the final manuscript.

Ethics approval and consent to participate

Not applicable.

\section{Consent for publication}

Not applicable.

\section{Competing interests}

The authors declare that they have no competing interests.

\section{Publisher's Note}

Springer Nature remains neutral with regard to jurisdictional claims in published maps and institutional affiliations.

\section{Author details}

${ }^{1}$ Embrapa Milho e Sorgo, Rodovia MG 424, km 65, Caixa Postal 151, Sete Lagoas, MG 35701-970, Brazil. Universidade Federal de Viçosa, Avenida Peter Henry Rolfs, s/n, Viçosa, MG 36570-900, Brazil. ²Departamento de Biologia Geral, Universidade Federal de Minas Gerais, Avenida Presidente Antônio Carlos, 6627, Belo Horizonte, MG 31270-901, Brazil. ${ }^{4}$ Global Institute for Food 
Security, University of Saskatchewan, Saskatoon, SK S7N 4J8, Canada. ${ }^{5}$ Present Address: Helix Sementes, Rua Arnaldo Luiz de Oliveira, 75, Setor D, Bela Vista, Patos de Minas, MG 38703-240, Brazil.

\section{Received: 22 October 2018 Accepted: 19 February 2019} Published online: 28 February 2019

\section{References}

1. De Wet JMJ, Harlan JR. The origin and domestication of Sorghum bicolor. Econ Bot. 1971;25:128-35 Springer.

2. Weltzien E, Rattunde H, Clerget B, Siart S, Toure A, Sagnard F. Sorghum diversity and adaptation to drought in West Africa. In: Jarvis D, Mar I, Sears $L$, editors. Enhancing use Crop Genet Divers to Manag abiotic Stress Agric Prod Syst; 2006. p. 31-8.

3. Doumbia MD, Hossner LR, Onken AB. Variable sorghum growth in acid soils of subhumid west africa. Arid Soil Res Rehabil. 1993;7:335-46.

4. Doumbia MD, Hossner LR, Onken AB. Sorghum growth in acid soils of West Africa: variations in soil chemical properties. Arid Soil Res Rehabil. 1998;12:179-90.

5. Leiser WL, Rattunde H, Weltzien E, Cisse N, Abdou M, Diallo A, et al. Two in one sweep: aluminum tolerance and grain yield in P-limited soils are associated to the same genomic region in west African Sorghum. BMC Plant Biol. 2014:14:206

6. Shaw JN. Iron and aluminum oxide characterization for highly-weathered Alabama ultisols. Commun Soil Sci Plant Anal. 2001:32:49-64.

7. Kochian LV. Cellular mechanisms of aluminum toxicity and resistance in plants. Annu Rev Plant Biol. 1995:46:237-60.

8. Marschner H. Mineral nutrition of higher plants. 2nd ed; 1995

9. Vance $\mathrm{CP}$, Uhde-Stone C, Allan DL. Phosphorus acquisition and use: critical adaptations by plants for securing a nonrenewable resource. New Phytol. 2003;157:423-47.

10. Lynch JP. Root phenes for enhanced soil exploration and phosphorus acquisition: tools for future crops. Plant Physiol. 2011;156:1041-9.

11. Hammond JP, Broadley MR, White PJ. Genetic responses to phosphorus deficiency. Ann Bot. 2004;94:323-32

12. Magalhaes JV, Liu J, Guimarães CT, Lana UGP, Alves VMC, Wang Y-H, et al. A gene in the multidrug and toxic compound extrusion (MATE) family confers aluminum tolerance in sorghum. Nat Genet. 2007:39:1156-61.

13. Carvalho G, Schaffert RE, Malosetti M, Viana JHM, Menezes CB, Silva LA, et al. Back to acid soil fields: The citrate transporter SbMATE is a major asset for sustainable grain yield for sorghum cultivated on acid soils. G3: Genes|Genomes|Genetics. 2016;6:475-84.

14. Drouillon M, Merckx R. The role of citric acid as a phosphorus mobilization mechanism in highly P-fixing soils. Gayana Bot. 2003;60:55-62.

15. Magalhaes JV, Piñeros MA, Maciel LS, Kochian LV. Emerging pleiotropic mechanisms underlying aluminum resistance and phosphorus acquisition on acidic soils. Front Plant Sci. Frontiers. 2018:9:1-12.

16. Parentoni SN, De Souza Júnior CL. Phosphorus acquisition and internal utilization efficiency in tropical maize genotypes. Pesqui Agropecu Bras. 2008:43:893-901.

17. López-Arredondo DL, Leyva-González MA, González-Morales SI, López-Bucio J, Herrera-Estrella L. Phosphate nutrition: improving low-phosphate tolerance in crops. Annu Rev Plant Biol. 2014;65:95-123.

18. Mendes FF, Guimarães LJM, Souza JC, Guimarães PEO, Magalhaes JV, Garcia AAF, et al. Genetic architecture of phosphorus use efficiency in tropical maize cultivated in a low-P soil. Crop Sci. 2014:54:1530-8.

19. Magalhaes JV, de Sousa SM, Guimaraes CT, Kochian LV. Chapter 7 - The role of root morphology and architecture in phosphorus acquisition: physiological, genetic, and molecular basis. In: Plant Macronutr Use Effic. London: Elsevier Inc; 2017. p.123-47.

20. Ho MD, Rosas JC, Brown KM, Lynch JP. Root architectural tradeoffs for water and phosphorus acquisition. Funct Plant Biol. 2005;32:737-48.

21. Gamuyao R, Chin JH, Pariasca-Tanaka J, Pesaresi P, Catausan S, Dalid C, et al. The protein kinase Pstol1 from traditional rice confers tolerance of phosphorus deficiency. Nature. 2012;488:535-9 Nature Publishing Group.

22. Hufnagel B, de Sousa SM, Assis L, Guimaraes CT, Leiser W, Azevedo GC, et al. Duplicate and conquer: multiple homologs of PHOSPHORUS STARVATION TOLERANCE1 enhance phosphorus acquisition and sorghum performance on low-phosphorus soils. Plant Physiol. 2014;166:659-77.

23. Sasaki T, Yamamoto Y, Ezaki B, Katsuhara M, Ahn SJ, Ryan PR, et al. A wheat gene encoding an aluminum-activated malate transporter. Plant J. 2004;37:645-53.
24. Iuchi S, Koyama H, luchi A, Kobayashi Y, Kitabayashi S, Kobayashi Y, et al. Zinc finger protein STOP1 is critical for proton tolerance in Arabidopsis and coregulates a key gene in aluminum tolerance. Proc Natl Acad Sci U S A. 2007;104:9900-5.

25. Larsen PB, Tai C, Kochian LV, Howell SH. Arabidopsis mutants with Increased sensitivity to aluminum. Plant Physiol. 1996:110:743-51.

26. Larsen PB, Geisler MJB, Jones CA, Williams KM, Cancel JD. ALS3 encodes a phloem-localized $A B C$ transporter-like protein that is required for aluminum tolerance in Arabidopsis. Plant J. 2005;41:353-63.

27. Belal R, Tang R, Li Y, Mabrouk Y, Badr E, Luan S. An ABC transporter complex encoded by aluminum sensitive 3 and NAP3 is required for phosphate deficiency responses in Arabidopsis. Biochem Biophys Res Commun. 2015:463:18-23 Elsevier Ltd.

28. Dong J, Piñeros MA, Li X, Yang H, Liu Y, Murphy AS, et al. An Arabidopsis $A B C$ transporter mediates phosphate deficiency-induced remodeling of root architecture by modulating iron homeostasis in roots. Mol Plant. 2017;10:244-59.

29. Balzergue C, Dartevelle T, Godon C, Laugier E, Meisrimler C, Teulon JM, et al. Low phosphate activates STOP1-ALMT1 to rapidly inhibit root cell elongation. Nat Commun. 2017:8:1-16.

30. Mora-Macías J, Ojeda-Rivera JO, Gutiérrez-Alanís D, Yong-Villalobos L, Oropeza-Aburto A, Raya-González J, et al. Malate-dependent Fe accumulation is a critical checkpoint in the root developmental response to low phosphate. Proc Natl Acad Sci. 2017;114:E3563-72.

31. Müller J, Toev T, Heisters M, Teller J, Moore KL, Hause G, et al. Irondependent callose deposition adjusts root meristem maintenance to phosphate availability. Dev Cell. 2015;33:216-30.

32. Moll RH, Kamprath EJ, Jackson WA. Analysis and interpretation of factors which contribute to efficiency of nitrogen utilization. Agron Journal. 1982; 74:562-4.

33. Magalhaes JV, Garvin DF, Wang Y, Sorrells ME, Klein PE, Schaffert RE, et al. Comparative mapping of a major aluminum tolerance gene in sorghum and other species in the Poaceae. Genetics. 2004;167:1905-14.

34. De Wet JMJ. Special paper: systematics and evolution of sorghum sect. Sorghum (Gramineae). Am J Bot. 1978;65:477-84 Wiley Online Library.

35. Leiser WL, Rattunde HFW, Piepho H-P, Weltzien E, Diallo A, Melchinger AE, et al. Selection strategy for sorghum targeting phosphorus-limited environments in West Africa: analysis of multi-environment experiments. Crop Sci. 2012;52:2517-27 The Crop Science Society of America, Inc.

36. Uga $Y$, Assaranurak I, Kitomi $Y$, Larson BG, Craft EJ, Shaff JE, et al. Genomic regions responsible for seminal and crown root lengths identified by 2D \& 3D root system image analysis. BMC Genomics. 2018;19:273 BioMed Central.

37. Zhu J, Lynch JP. The contribution of lateral rooting to phosphorus acquisition efficiency in maize (Zea mays) seedlings. Funct Plant Biol CSIRO. 2004:31:949-58

38. Wu Q, Pagès $L$, Wu J. Relationships between root diameter, root length and root branching along lateral roots in adult, field-grown maize. Ann Bot. 2016;117:379-90 Oxford University Press.

39. Eissenstat DM. Costs and benefits of constructing roots of small diameter. J Plant Nutr. 1992;15:763-82 Taylor \& Francis.

40. Gong X, McDonald G. QTL mapping of root traits in phosphorus-deficient soils reveals important genomic regions for improving NDVI and grain yield in barley. Theor Appl Genet. 2017:130:1885-902 Springer.

41. Azevedo GC, Cheavegatti-Gianotto A, Negri BF, Hufnagel B, Silva Lda C, Magalhaes JV, et al. Multiple interval QTL mapping and searching for PSTOL1 homologs associated with root morphology, biomass accumulation and phosphorus content in maize seedlings under low-P. BMC Plant Biol. 2015;15:172.

42. Zhang H, Uddin MS, Zou C, Xie C, Xu Y, Li W-X. Meta-analysis and candidate gene mining of low-phosphorus tolerance in maize. J Integr Plant Biol. 2014;56:262-70 Wiley Online Library.

43. Sabadin PK, Malosetti M, Boer MP, Tardin FD, Santos FG, Guimarães CT, et al. Studying the genetic basis of drought tolerance in sorghum by managed stress trials and adjustments for phenological and plant height differences. Theor Appl Genet. 2012;124:1389-402.

44. Liu T-Y, Huang T-K, Tseng C-Y, Lai Y-S, Lin S-I, Lin W-Y, et al. PHO2dependent degradation of pho1 modulates phosphate homeostasis in Arabidopsis. Plant Cell. 2012:24:2168-83.

45. Du Q, Wang K, Zou C, Xu C, Li W-X. The PILNCR1-miR399 regulatory module is important for low phosphate tolerance in maize. Plant Physiol. Am Soc Plant Biol. 2018;177:1743-53. 
46. Talboys PJ, Healey JR, Withers PJA, Jones DL. Phosphate depletion modulates auxin transport in Triticum aestivum leading to altered root branching. J Exp Bot. 2014;65:5023-32 Oxford University Press UK.

47. Johnson HW, Bernard RL. Soybean genetics and breeding. Adv Agron. 1962; 14:149-221.

48. Schaffert RE, Alves VMC, Pitta GVE, Bahia AFC, Santos FG. Genetic variability in sorghum for $P$ efficiency and responsiveness. In: Horst WJ, Schenk MK, Bürkert A, Claassen N, Flessa H, Frommer WB, et al., editors. Plant Nutr Dev Plant Soil Sci. Dordrecht: Springer; 2001. p. 72-3.

49. Morais De Sousa S, Clark RT, Mendes FF, Carlos De Oliveira A, Vilaça De Vasconcelos MJ, Parentoni SN, et al. A role for root morphology and related candidate genes in $\mathrm{P}$ acquisition efficiency in maize. Funct Plant Biol. 2012;39:925-35.

50. Hund A, Trachsel S, Stamp P. Growth of axile and lateral roots of maize: I development of a phenotying platform. Plant Soil. 2009:325:335-49.

51. Magnavaca R, Gardner COE, Clark RB. Inheritance of aluminum tolerance in maize. In: Gabelman WH, Loughman BC, editors. Genet Asp Plant Miner Nutr Dev Plant Soil Sci. Dordrecht: Springer; 1987. p. 201-12.

52. Wald A. Tests of statistical hypotheses concerning several parameters when the number of observations is large. Trans Am Math Soc. 1943;54:426-82.

53. Neyman J, Pearson ES. On the use and interpretation of certain test criteria for purposes of statistical inference: part I. Biometrika. 1928;20A:175-240.

54. VSN International. GenStat for Windows. 17th ed. Hemel Hempstead: VSN Internacional; 2014. Available from: GenStat.co.uk

55. Cullis BR, Smith AB, Coombes NE. On the design of early generation variety trials with correlated data. J Agric Biol Environ Stat. 2006;11:381-93.

56. Pearson K. Mathematical contributions to the theory of evolution. III. Regression, heredity, and Panmixia. Philos Trans R Soc London Ser a, Contain Pap a Math or Phys Character. 1895;187:253-318.

57. Harrell Jr FE. With contributions from Charles Dupont and many others. Hmisc: Harrell Miscellaneous. 2015. R package version 3.17-4.

58. Team RC. R: a language and environment for statistical computing. Viena: R Foundation for Statistical Computing; 2016. Available from: https://www.r-project.org/

59. Saghai-Maroof MA, Soliman KM, Jorgensen RA, Allard RW. Ribosomal DNA spacer-length polymorphisms in barley: mendelian inheritance, chromosomal location, and population dynamics. Proc Natl Acad Sci. 1984; 81:8014-8.

60. Elshire RJ, Glaubitz JC, Sun Q, Poland JA, Kawamoto K, Buckler ES, et al. A robust, simple genotyping-by-sequencing (GBS) approach for high diversity species. PLoS One. 2011;6:1-10.

61. Li H, Durbin R. Fast and accurate short read alignment with burrows-wheeler transform. Bioinformatics. 2009;25:1754-60 Oxford University Press.

62. Glaubitz JC, Casstevens TM, Lu F, Harriman J, Elshire RJ, Sun Q, et al. TASSEL-GBS: A high capacity genotyping by sequencing analysis pipeline. PLoS One. 2014;9:e90346.

63. Bradbury PJ, Zhang Z, Kroon DE, Casstevens TM, Ramdoss Y, Buckler ES. TASSEL: software for association mapping of complex traits in diverse samples. Bioinformatics. 2007;23:2633-5.

64. Roberts A, McMillan L, Wang W, Parker J, Rusyn I, Threadgill D. Inferring missing genotypes in large SNP panels using fast nearest-neighbor searches over sliding windows. Bioinformatics. 2007;23:401-7.

65. Silva LDCE, Wang S, Zeng Z-B. Multiple trait multiple interval mapping of quantitative trait loci from inbred line crosses. BMC Genet. 2012;13:67.

66. Haley CS, Knott SA. A simple regression method for mapping quantitative trait loci in line crosses using flanking markers. Heredity (Edinb). 1992;69:315-24.

67. Zou F, Fine JP, Hu J, Lin DY. An efficient resampling method for assessing genome-wide statistical significance in mapping quantitative trait loci. Genetics. 2004:168:2307-16.

68. Zellner A. An efficient method of estimating seemingly unrelated regressions and tests for aggregation bias. J Am Stat Assoc. 1962:57:348-68 Taylor \& Francis.

69. Schmittgen TD, Livak KJ. Analyzing real-time PCR data by the comparative CT method. Nat Protoc. 2008:3:1101-8.

Ready to submit your research? Choose BMC and benefit from:

- fast, convenient online submission

- thorough peer review by experienced researchers in your field

- rapid publication on acceptance

- support for research data, including large and complex data types

- gold Open Access which fosters wider collaboration and increased citations

- maximum visibility for your research: over $100 \mathrm{M}$ website views per year

At $\mathrm{BMC}$, research is always in progress.

Learn more biomedcentral.com/submissions 